\title{
Graphene Oxide Wrapped SERS Tags: Multifunctional Platforms toward Optical Labeling, Photothermal Ablation of Bacteria, and the Monitoring of Killing Effect
}

\author{
Donghai Lin, ${ }^{\dagger, \S}$ Tianqi Qin, ${ }^{\dagger, \S}$ Yunqing Wang, ${ }^{*}{ }^{\ddagger}$ Xiuyan Sun, ${ }^{\dagger}$ and Lingxin Chen ${ }^{*}{ }^{\ddagger}$ \\ ${ }^{\dagger}$ School of Pharmacy, Yantai University, Yantai 264005, China \\ ${ }^{\ddagger}$ Key Laboratory of Coastal Environmental Processes and Ecological Remediation, Yantai Institute of Coastal Zone Research, Chinese \\ Academy of Sciences, Yantai 264003, China
}

\section{Supporting Information}

ABSTRACT: As novel optical nanoprobes, surface-enhanced Raman scattering (SERS) tags have drawn growing interests in the application of biomedical imaging and phototherapies. Herein, we demonstrated a novel in situ synthesis strategy for GO wrapped gold nanocluster SERS tags by using a tris $\left(2,2^{\prime}\right.$-bipyridyl)ruthenium(II) chloride (Rubpy)/GO nanohybrid as a complex Raman reporter, inspired by the role of GO as an artificial receptor for various dyes. The introduction of GO in the synthesis procedure provided systematic solutions for controlling several key parameters of SERS tags, including reproducibility, sensitivity, and colloidal and signal stability. An additional interesting thermal-sensitive SERS property (SERS intensity decreased upon increasing the temperature) was also achieved due to the heat-induced release/redistribution of reporter molecules adsorbed on GO. Combining the synergic effect of these features, we further fabricated multifunctional, aldehyde group conjugated Au@Rubpy/GO SERS tags for optical labeling and photothermal ablation of bacteria. Sensitive Raman imaging of gram-positive (Staphylococcus aureus) and gram-negative (Escherichia coli) bacteria could be realized, and satisfactory photothermal killing efficacy for both bacteria was achieved. Our results also demonstrated the correlation among the SERS intensity decrease ratio, bacteria survival rate, and the terminal temperature of the tag-bacteria suspension, showing the possibility to use SERS assay to measure antibacterial response during the photothermal process using this tag.

KEYWORDS: graphene oxide, gold nanoparticles, SERS tags, bacteria, photothermal ablation

\section{INTRODUCTION}

Surface-enhanced Raman scattering (SERS) tags are novel optical nanoprobes that combine noble metallic nanoparticles (NPs) and specific organic Raman reporter molecules. SERS tags produce strong characteristic Raman signals of Raman reporters and inherit ultrasensitivity, multiplexing, and quantitative abilities of the SERS technique, showing extraordinary features over traditional fluorescent dyes and quantum dots. ${ }^{1}$ SERS tags were successfully applied for chemical and biological analysis at different levels of ionic or molecular detection, ${ }^{2-5}$ live-cell sensing, ${ }^{6}$ tissue diagnosis, and in vivo bioimaging. ${ }^{7}$ In recent years, there has been growing popularity of the design and fabrication of SERS tag-based multifunctional nanoplatforms combining SERS imaging and drug delivery ${ }^{8,9}$ or phototherapy. ${ }^{10}$

Graphene oxide (GO), as the oxidized form of graphene, has a unique chemical structure composed of segregated $\mathrm{sp}^{2}$ carbon domains among $\mathrm{sp}^{3}$ carbons presenting various oxygencontaining functional groups. ${ }^{11}$ Because of its distinct physical properties, such as superior molecule adsorption ability, water dispersibility, fluorescent emission, and Raman scattering features, GO has attracted much attention in the biological applications, including drug delivery ${ }^{12}$ and constructing chemical sensors. ${ }^{13-16}$ Lately, researchers found that GO also showed great potential in SERS investigation due to the fluorescence quenching, and an additional SERS chemical enhancing ability. ${ }^{17,18}$ Rational combination of GO and noble metal NPs could dramatically improve the conventional SERS performance in various aspects by taking advantage of GO's different roles. For example, AuNP/ $/ \mathrm{GO}^{19-22}$ and AgNP/ $\mathrm{GO}^{23-25}$ hybrids were fabricated by either doping NPs or in situ NP growth on the GO sheet, acting as controlled NP oriented substrates with large surface areas and high SERS activity. Besides, GO was proved as an effective additive for SERS detection performed in a Ag NPs colloid, which was helpful to generate stable hotspots with high yield that led to a highly reproducible, stable, and sensitive SERS signal for a wide range of analytes. ${ }^{26}$ Moreover, $\mathrm{Au} / \mathrm{GO}$ NPs were also reported as novel SERS tags for intracellular imaging ${ }^{27-29}$ and drug delivery. ${ }^{30}$ In these tags, GO served as a Raman reporter and

Received: November 26, 2013

Accepted: December 31, 2013

Published: December 31, 2013 
Scheme 1
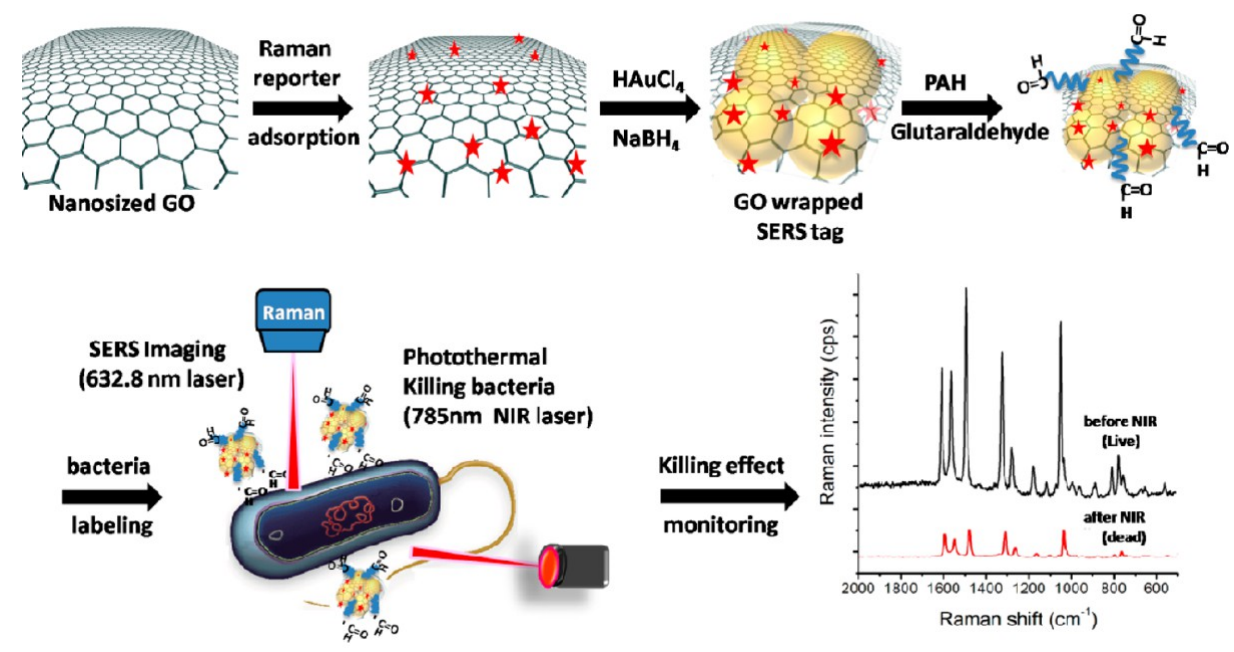

the signal was much enhanced by Au NPs compared with that of GO itself. However, GO is not an ideal Raman reporter candidate from the consideration of the Raman cross section, the match of the light absorption with incident laser, and the richness of Raman peak signatures. Therefore, there remains plenty of room to increase the sensitivity and multiplex labeling ability of Au/GO hybrid SERS tags.

Herein, we report novel GO wrapped SERS tags with strong and characteristic signals by in situ reduction of $\mathrm{Au}^{3+}$ in the Raman reporter (tris(2,2'-bipyridyl)ruthenium(II) chloride, Rubpy)/GO complex solution, inspired by the role of GO as artificial receptors for various dyes. As shown in Scheme 1, the Rubpy/GO complex was first formed by using GO as a dye molecule enricher due to GO's high affinity toward aromatic groups through $\pi-\pi$ stacking and electrostatic interaction. ${ }^{31}$ Then controllable numbers of gold NPs in situ grew on GO with the Raman reporter as a linking site and finally being wrapped, producing a local electromagnetic (EM) field and the resultant strong SERS signals of Raman reporters. The introduction of GO in the synthesis of SERS tags provides systematic solutions for several key issues (reproducibility, sensitivity, and stability) in typical synthesis ways. First, the morphology and optical property of tags are controllable. Au clusters with different aggregation extents can be obtained by using different-sized GO. The samples with near-infrared (NIR) absorption are easily attainable for further photothermal application. Second, high density of the Raman reporter can be enriched on GO sheets, rendering the high sensitivity of the tags. Third, GO forms an ultrathin (about $1 \mathrm{~nm}$ ), transparent capping sheath of the tags, and thus the adsorbed Raman reporters "feel" the EM field with high efficiency for SERS enhancement, and the scattering signals export nearly without loss. ${ }^{18}$ Fourth, the compact GO coating maintains the good water dispersibility and assures the tags' colloidal and signal stability in the biological matrix.

To illustrate the application of these properties, multifunctional SERS tags were fabricated for optical labeling, photothermal ablation of bacteria, and the monitoring of the killing effect via the thermal-sensitive SERS signal response. After adsorbing positively charged poly(allylamine hydrochloride) (PAH) on Au@Rubpy/GO SERS tags by electrostatic force and subsequent conjugating the bacteria affinitive ligand of the aldehyde group, the labeling and fast Raman imaging of both gram-positive (Staphylococcus aureus, S. aureus) and gramnegative (Escherichia coli, E. coli) bacteria were realized. Furthermore, excellent photothermal ablation results were obtained for both bacteria. Owing to the thermal-sensitive feature of this SERS tag, the potential of in situ monitoring of the photothermal antibacterial response using SERS assay was demonstrated.

\section{EXPERIMENTAL SECTION}

Materials. Hydrogen tetrachloroaurate $\left(\mathrm{HAuCl}_{4} \cdot 3 \mathrm{H}_{2} \mathrm{O}\right)$, sodium citrate, sodium tetrahydridoborate $\left(\mathrm{NaBH}_{4}\right)$, and glutaraldehyde (GA) were purchased from Sinopharm Chemical Reagent Co., Ltd. Graphene oxide (GO) was purchased from Nanjing XF NANO Materials Tech Co., Ltd. Tris(2,2'-bipyridyl)ruthenium(II) chloride (Rubpy) and bovine serum albumin (BSA) were obtained from SigmaAldrich. Au NPs $(13 \mathrm{~nm})^{32}$ and Au nanorods (AuNRs) ${ }^{33}$ were prepared according to a literature procedure. Staphylococcus aureus and Escherichia coli strains were obtained from the China General Microbiological Culture Collection Center. The Luria-Bertani (LB) medium was prepared by mixing $10 \mathrm{~g}$ of tryptone, $5 \mathrm{~g}$ of yeast extract, and $10 \mathrm{~g}$ of $\mathrm{NaCl}$ in $950 \mathrm{~mL}$ of deionized water. Milli-Q ultrapure water was used in all of the experiments. Denatured BSA (thio-BSA) was prepared by treating BSA with $\mathrm{NaBH}_{4}$ according to a literature procedure. $^{34}$

Characterization. The transmission electron microscopy (TEM) images were acquired on a JEM-1400 transmission electron microscope (JEOL, Japan). The field emission scanning electron microscopy (FE-SEM) images were acquired on an S-4800 field emission scanning electron microscope (Hitachi, Japan). Atomic force microscopy (AFM) images were obtained on an atomic force microscope (Veeco, USA). UV/vis/NIR absorption spectra were recorded on a Thermo Scientific NanoDrop 2000/2000C spectrophotometer. SERS spectra were recorded by using a DXR Raman Microscope (Thermal Fisher, USA). A $632.8 \mathrm{~nm}$ He:Ne laser was focused by a $50 \times$ microscope objective with a power of $3 \mathrm{~mW}$. The exposure time was 4 $\mathrm{s}$, and each of the signals was collected twice. Fluorescence measurements were carried out on a FluoroMax-4 spectrofluorometer (HORIBA, France). The hydrodynamic diameters of the nanoparticles in solution were measured on a Zetasizer Nano ZS90 (Malvern, U.K.).

GO Solution Preparation. The GO solution $(2 \mathrm{mg} / \mathrm{mL}, 10 \mathrm{~mL})$ was treated with an ultrasonic probe $(200 \mathrm{~W}, 20 \mathrm{~min})$ and centrifuged at $5000 \mathrm{rpm}$ for $20 \mathrm{~min}$. The supernatant was collected and then centrifuged at $14000 \mathrm{rpm}$ for $20 \mathrm{~min}$. The sediment was redispersed in $4 \mathrm{~mL}$ of water and used as the large GO sheet (L-GO) stock solution. The UV absorption at $400 \mathrm{~nm}$ was 0.27 for its $50 \times$ dilution. Another GO solution $(2 \mathrm{mg} / \mathrm{mL}, 10 \mathrm{~mL})$ was treated with an ultrasonic probe $(200 \mathrm{~W}, 2 \mathrm{~h})$ and then ultracentrifuged at $30000 \mathrm{rpm}$ for $20 \mathrm{~min}$. The 
supernatant was carefully separated as the small GO sheet (S-GO) stock solution. The UV absorption at $400 \mathrm{~nm}$ was 0.32 for its $25 \times$ dilution.

Fluorescence Titration. The optimum ratio of GO and Raman reporter Rubpy was determined by fluorescent titrations conducted by titrating increasing GO concentrations against a constant Rubpy concentration $\left(10^{-5} \mathrm{M}\right)$ at a volume of $1.0 \mathrm{~mL}$. The mixtures were allowed to equilibrate for $10 \mathrm{~min}$ at room temperature before measurement. The excitation wavelength was $505 \mathrm{~nm}$, and the excitation/emission slit was $5.0 / 5.0 \mathrm{~nm}$.

Au@Rubpy/GO SERS Tags Synthesis. Au@Rubpy/GO NPs were fabricated by a one-step synthesis method. Different volumes of Rubpy/GO complex solution (50, 100, 150, 200, 250, 300, 350, 400, 450 , and $500 \mu \mathrm{L}$ ) were diluted to $1.0 \mathrm{~mL}$ with water. A $10 \mu \mathrm{L}$ portion of sodium citrate $(25 \mathrm{mM})$ and $20 \mu \mathrm{L}$ of $\mathrm{HAuCl}_{4}(50 \mathrm{mM})$ were added to the mixture in sequence. Then a $12 \mu \mathrm{L}$ ice-cold $\mathrm{NaBH}_{4}$ solution $(0.1 \mathrm{M})$ was added with vigorous agitation. After $10 \mathrm{~min}$, the formed Au@Rubpy/GO SERS tags were collected by centrifugation $(10000 \mathrm{rpm} / 8 \mathrm{~min})$ and dispersed in water, followed by mild sonication. To synthesize glutaraldehyde-modified SERS tags for bacteria capture, $200 \mu \mathrm{L}$ of PAH solution $(2 \mathrm{mg} / \mathrm{mL})$ was added to 1 $\mathrm{mL}$ of Au@Rubpy/L-GO solution. After $30 \mathrm{~min}$, the mixture was centrifuged $(10000 \mathrm{rpm} / 8 \mathrm{~min})$ for three times and redispersed to 1 $\mathrm{mL}$ of water. Then $50 \mu \mathrm{L}$ of GA solution (25\%) was added to the PAH labeled Au@Rubpy/L-GO solution for reaction for $30 \mathrm{~min}$, after which the mixture was centrifuged $(10000 \mathrm{rpm} / 8 \mathrm{~min})$ for three times and redispersed to $200 \mu \mathrm{L}$ of PBS. The GA-modified SERS tag solution was sterilized under a $365 \mathrm{~nm}$ lamp $(125 \mathrm{~W})$ for $30 \mathrm{~min}$ before the bacteria capturing experiment.

Synthesis of AuNPs (13 nm) Cluster Based SERS Tags. The typical structured SERS tag was synthesized by Rubpy $\left(10^{-5} \mathrm{M}, 80\right.$ $\mu \mathrm{L})$ induced aggregation of $13 \mathrm{~nm}$ AuNPs $(0.5 \mathrm{~mL})$, which were further protected by denatured bovine serum albumin (thio-BSA, 50 $\mu \mathrm{L})$. The mixture solution was centrifuged $(10000 \mathrm{rpm} / 8 \mathrm{~min})$ and redispersed in $500 \mu \mathrm{L}$ of water.

Bacteria Culture. Before each microbiological experiment, all samples and glassware were sterilized by autoclaving at $121{ }^{\circ} \mathrm{C}$ for 30 min. Cultures of $S$. aureus and E. coli strains were grown on nutrient agar overnight, transferred into an Erlenmeyer flask containing LB nutrient broth at an initial optical density (OD600) of 0.1 at $600 \mathrm{~nm}$, and allowed to grow at $37^{\circ} \mathrm{C}$ under $200 \mathrm{rpm}$ rotation. When the cultures reached an OD600 of 0.74 for S. aureus and 0.43 for E. coli, they were centrifuged and washed twice with PBS to yield final bacterial solutions.

Photothermal Treatments. To examine the photothermal effect of the Au@Rubpy/L-GO SERS tag, $1 \mathrm{~mL}$ of the as-prepared solution was irradiated for $10 \mathrm{~min}$ by a NIR laser $(785 \mathrm{~nm}, 400 \mathrm{~mW})$ at a distance of $1 \mathrm{~cm}$ from the side of the sample solution in a $1.5 \mathrm{~mL}$ Eppendorf tube. A thermoindicator was used to monitor the temperature change of the sample solutions. Pure water and Rubpy/ GO complex solution were utilized as negative controls, and AuNR (the longitude absorption is $780 \mathrm{~nm}$ ) solution with the same concentration of $\mathrm{Au}$ element was utilized as a positive control. To test the bacteria killing ability, different volumes of GA-modified SERS tag solutions $(25,50$, and $100 \mu \mathrm{L})$ were diluted to $100 \mu \mathrm{L}$ with PBS ( $\mathrm{pH}$ 7.4). A $10 \mu \mathrm{L}$ portion of bacteria solution was mixed with the above SERS tag solutions, followed by irradiation for $5 \mathrm{~min}$ by a NIR laser $(785 \mathrm{~nm}, 400 \mathrm{~mW})$. The SERS intensity and the temperature of the mixtures before and after irradiation were measured. After irradiation, the bacteria remaining in the mixture were diluted $10^{3}$ times, and $50 \mu \mathrm{L}$ of the dilution was placed on a Petri dish containing $\mathrm{LB}$ medium and cultured at $37^{\circ} \mathrm{C}$ for $12 \mathrm{~h}$. The control experiments of S. aureus and E. coli incubated in PBS buffer, incubated in PBS buffer encountering NIR irradiation, and incubated with $100 \mu \mathrm{L}$ of SERS tags without NIR irradiation were also performed.

\section{RESULTS AND DISCUSSION}

Synthesis of Au@Rubpy/GO SERS Tags. Two differentsized GO solutions were obtained by using different probe sonication and centrifugation treatment conditions. Atomic force microscopy images revealed the size of small GO (denoted as S-GO) and large GO (denoted as L-GO) was around 100 and $340 \mathrm{~nm}$, respectively (Figure $1 \mathrm{a}, \mathrm{b}$ ). The

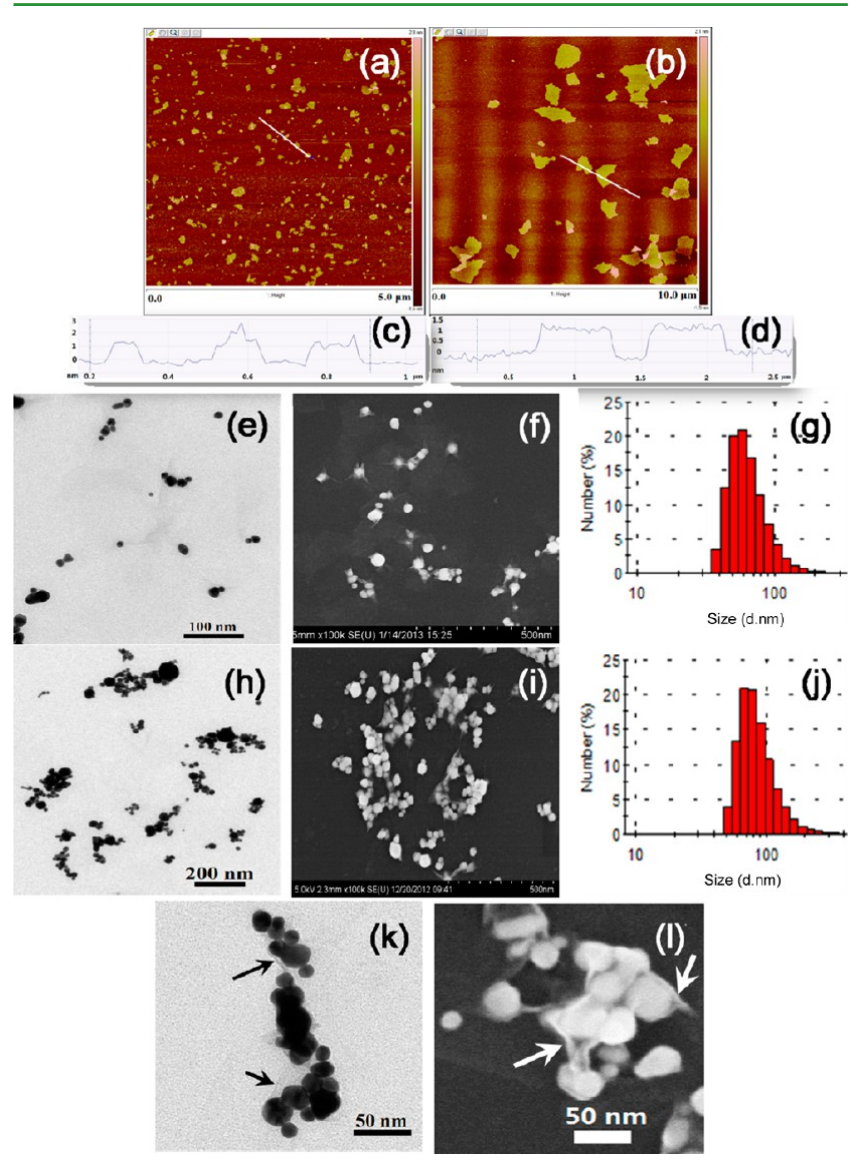

Figure 1. Morphology characterization of Au@Rubpy/GO SERS tags. AFM images of S-GO (a) and L-GO (b), and the corresponding crosssectional height profiles $(c, d)$ taken along the white straight line. The GO dispersion was cast onto a freshly prepared mica wafer, followed by drying at $80{ }^{\circ} \mathrm{C}$. Panels (e) and (f) represent TEM and SEM images of the Au@Rubpy/S-GO; panels (h) and (i) represent TEM and SEM images of Au@Rubpy/L-GO SERS tags. Panels $(\mathrm{g})$ and $(\mathrm{j})$ show the size distributions of Au@Rubpy/S-GO and Au@Rubpy/LGO SERS tags, respectively, measured by dynamic light scattering. Panels (k) and (1) illustrate high-resolution TEM and SEM images of the Au@Rubpy/L-GO SERS tag, showing the GO wrapped Au cluster structure.

corresponding cross-sectional height profile showed that GO of both sizes was single-layered (Figure 1c,d). Different from a conventional SERS tag synthesis procedure, the Raman reporter molecules were loaded on GO sheets before encountering metal substrates. The loading content of the Raman reporter (Rubpy) was determined via fluorescence titration based on the quenching effect of $\mathrm{GO}$ on the adsorbed fluorophores. As demonstrated in Figure S1a,b in the Supporting Information, the fluorescence of the $10^{-5} \mathrm{M}$ Rubpy solution $(1.0 \mathrm{~mL})$ decreased gradually and reached stable with the addition of both $60 \mu \mathrm{L}$ of S-GO and $30 \mu \mathrm{L}$ of L$\mathrm{GO}$, respectively. To make sure the complete adsorption of free Rubpy in solution, the amounts of $80 \mu \mathrm{L}$ for S-GO and $40 \mu \mathrm{L}$ for L-GO were used in the following synthesis process. UV-vis absorbance measurements revealed that the Rubpy/GO 

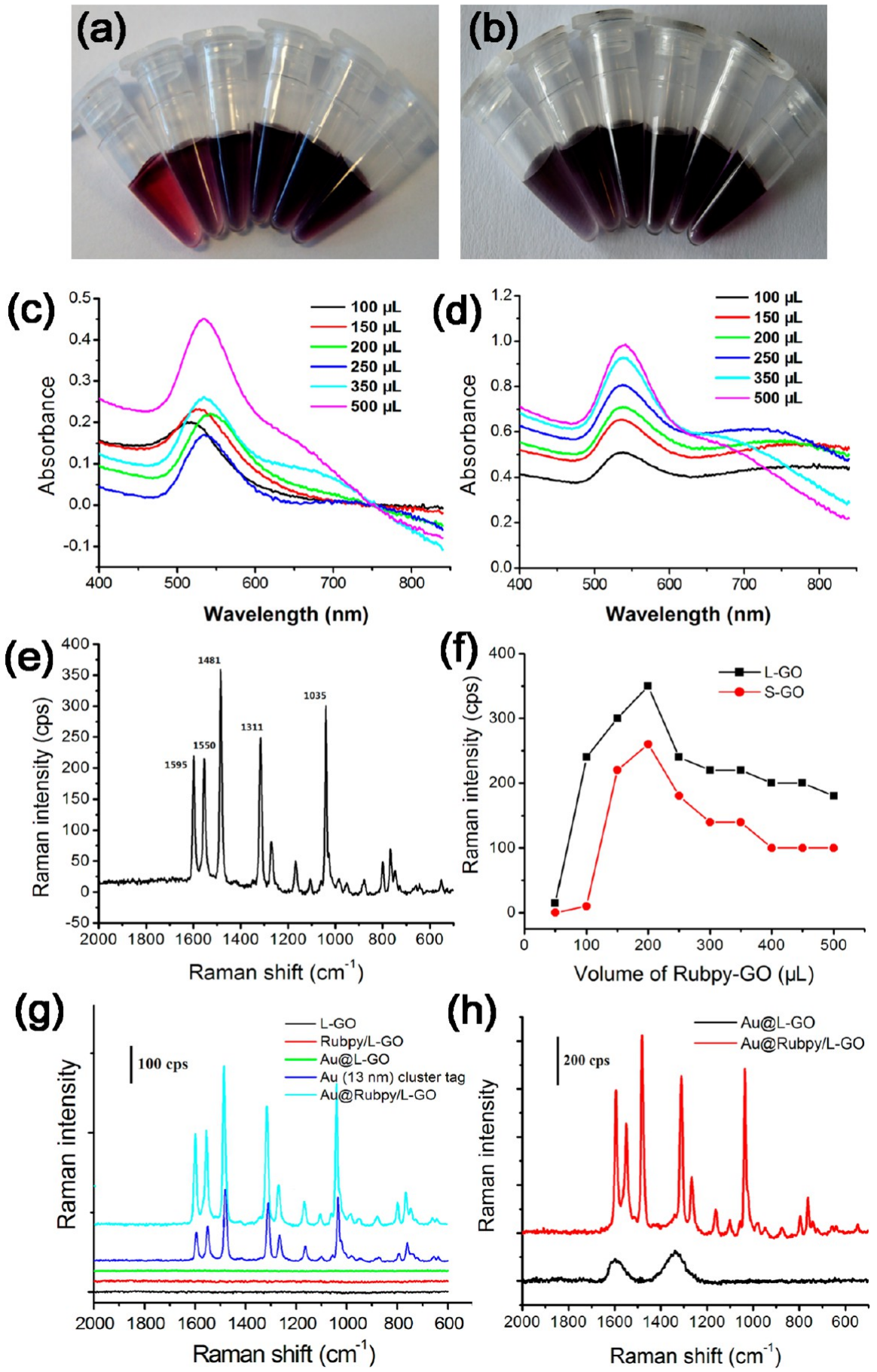

Figure 2. Optical characterization of Au@Rubpy/GO SERS tags. Photos of Au@Rubpy/S-GO (a) and Au@Rubpy/L-GO (b) SERS tag solutions prepared by adding different amounts of Rubpy/GO complex solutions $\left(100,150,200,250,350\right.$, and $500 \mu \mathrm{L}$ from left to right) in $1 \mathrm{~mL}$ of $\mathrm{Au}^{3+}$ growth solution (1 mM). UV/vis/NIR spectra of (c) Au@Rubpy/S-GO and (d) Au@Rubpy/L-GO prepared by adding different amounts of Rubpy/GO complex solutions. (e) Raman spectra of Au@Rubpy/L-GO SERS tag prepared by adding $200 \mu \mathrm{L}$ of Rubpy/GO complex solution to gold growth solution. (f) SERS intensity of the characteristic peak of $1481 \mathrm{~cm}^{-1}$ of Au@Rubpy/S-GO and Au@Rubpy/L-GO SERS tags with increasing amount of Rubpy/GO complex. (g) The Raman signal of GO, Rubpy/GO, Au@GO (without Rubpy), Au NP (13 nm) cluster tag, and Au@Rubpy/L-GO tag solutions with the same GO, Rubpy, or gold concentration. (h) The Raman spectra of Au@GO (without Rubpy) and Au@ Rubpy/L-GO tags drop-coated on clean silicon wafer, followed by air-drying.

complex had a sum-up spectra of those of both (Figure S1c,d, Supporting Information). The $\zeta$ potential increased from -42.5 $\mathrm{mV}$ for S-GO to $-26.5 \mathrm{mV}$ for the Rubpy/S-GO complex and $-52.2 \mathrm{mV}$ for L-GO to $-34.3 \mathrm{mV}$ for the Rubpy/L-GO complex. Dynamic light scattering (DLS) measurements revealed that, with Rubpy attaching, the size of GO did not change obviously (Figure S2, Supporting Information), showing that the Rubpy attachment did not cause the aggregation of the GO sheet.

The Au@Rubpy/GO NPs were fabricated by an in situ reduction synthesis method. $\mathrm{HAuCl}_{4}$ was mixed with Rubpy/ GO complex solution, and $\mathrm{NaBH}_{4}$ solution was then added 
under vigorous agitation. After $10 \mathrm{~min}$, the formed $\mathrm{Au} @$ Rubpy/GO SERS tags were collected by centrifugation and dispersed in $\mathrm{H}_{2} \mathrm{O}$, followed by mild sonication. The morphology of the SERS tags was characterized by transmission electron microscopy (TEM) and field emission scanning electron microscopy (FE-SEM). At the optimized condition (with $200 \mu \mathrm{L}$ of Rubpy/GO complex solution), the $\mathrm{Au} @$ Rubpy/S-GO tags were composed of a small cluster (no more than $4 \mathrm{Au}$ NPs) with a diameter of around $50 \mathrm{~nm}$ (Figure 1e,f). Comparatively, the Au@Rubpy/L-GO samples were composed of more $\mathrm{Au}$ NPs and were bigger in size, with diameters of around $150 \mathrm{~nm}$ (Figure 1h,i). The size distribution of Au NPs in Au@Rubpy/L-GO tags was analyzed, and more than 70\% of $\mathrm{Au}$ NPs had a diameter in the range of 10-20 nm (Figure S3, Supporting Information). Besides, it was found that the varied concentration of GO did not obviously influence the formation and size of Au clusters (Figure S4, Supporting Information). Interestingly, GO sheets were found wrapped on the compact $\mathrm{Au}$ NP clusters, which could be clearly observed in both the TEM and the FE-SEM images, indicated by the arrows (Figure $1 \mathrm{k}, 1)$. Similar wrapping shells were reported in other hybrids composed of $\mathrm{GO}$ and $\mathrm{Au} \mathrm{NPs},{ }^{30}$ metal oxide, ${ }^{35}$ anatase $\mathrm{TiO}_{2}{ }^{36}$ and mesoporous silica, ${ }^{37}$ which provided protective functions for the encapsulated NPs. The hydrodynamic size of the Au@ Rubpy/S-GO and Au@Rubpy/L-GO tags in water measured by DLS was determined to be 111.6 and $192.8 \mathrm{~nm}$, respectively (Figure 1g,j), which is smaller than those of the Rubpy/GO precursors (132.6 and $346.5 \mathrm{~nm}$, respectively) shown in Figure S2 (Supporting Information). The size decrease could be attributed to the folding of GO to a wrapping shell from flat sheets. Moreover, the $\zeta$ potential of Au@Rubpy/L-GO tags was determined to be $-25.8 \mathrm{mV}$. The negative $\zeta$ potential value further supported the GO wrapping on the AuNP cluster surface. As is well-known, precise control of the shape and size of the aggregated NPs is essential to fabricate homogeneous, nanosized SERS tags. Salt-induced ${ }^{38,39}$ and dye-induced aggregation $^{40}$ methods were widely used, and polymers such as polyvinylpyrrolidone (PVP) ${ }^{39}$ are essential to quench the aggregation process by forming a shell on the NP's surface. Herein, our results revealed the introduction of GO in the synthesis of SERS tags realizing the AuNP cluster (hotspot) formation, size and morphology controlling, and surface coating in one step.

Optical Properties of Au@Rubpy/GO SERS Tags. Optical absorption and SERS properties of Au@Rubpy/GO SERS tags were carefully studied using samples prepared under different conditions. The digital photos of Au@Rubpy/S-GO and Au@Rubpy/L-GO tag solutions synthesized by introducing different amounts of Rubpy/GO complex to $1 \mathrm{mM} \mathrm{Au}{ }^{3+}$ growth solutions (Figure 2a,b) clearly showed the color change with addition of $\mathrm{NaBH}_{4}$. UV/vis/NIR spectra (Figure 2c,d) showed that, with the increasing amount of Rubpy/GO complex, the absorption of Au@Rubpy/S-GO tags in NIR region slightly increased. This phenomenon was more obvious for Au@Rubpy/L-GO; a continuous absorption band from the visible to NIR regions appeared. The strong surface plasmon resonance NIR absorption was contributed by the compact $\mathrm{Au}$ NP clusters embedded in GO, which could be utilized for the subsequent photothermal ablation of bacteria. Further increasing the concentration of the Rubpy/GO complex meant that the area for $\mathrm{Au} \mathrm{NPs}$ attaching enlarged; therefore, the NP density on the GO sheet decreased. This led to the large clusters become fewer and the absorption in the NIR region decreased.

In Raman measurements of both Au@Rubpy/S-GO and Au@Rubpy/L-GO SERS tag samples, the characteristic peaks of Rubpy $^{41,42}$ at $1595,1550,1481,1311$, and $1035 \mathrm{~cm}^{-1}$ were observed (Figure 2e). The SERS signal intensity first rose with the increasing addition of Rubpy/GO complex and reached the optimum volume of $200 \mu \mathrm{L}$, after which obviously decreased values were observed (Figure 2f). This is owing to that the optimum condition provided more Au clusters, i.e., hotspots that possess a much stronger Raman signal enhancing ability than a single $\mathrm{Au}$ NP has. The SERS intensity changing trend is consistent with the results of UV/vis/NIR spectra characterization. To illustrate the synergic contribution of Rubpy and GO for the sensitivity improvement of SERS tags, we compared the Raman spectra of Au@Rubpy/L-GO tags with the synthesis precursor (GO and Rubpy/GO complex) and two published structured SERS tags, i.e., Au@GO NP (using GO as Raman reporter) and thio-BSA stabilized Au NP (13 nm) cluster SERS tags (the SEM and UV/vis/NIR characterizations are shown in Figure S5, Supporting Information). In all samples, the concentrations of GO, Rubpy, or gold element were the same. As shown in Figure $2 \mathrm{~g}$, the Au NP $(13 \mathrm{~nm})$ cluster tag solution showed Rubpy characteristic peaks, while it only had half of the intensity of Au@Rubpy/L-GO tags. The Raman signal of GO, Rubpy/GO, and Au@GO solution was too weak to be detected. GO contributed to the high sensitivity of $\mathrm{Au} @$ Rubpy/L-GO tags with comprehensive effects. On one hand, during in situ $\mathrm{Au}$ growth on $\mathrm{GO}$, the formed $\mathrm{Au}$ seeds were very small at the nucleation process; thus, multiple seeds could attach on one nanoscale GO sheet. This laid the foundation for the formation of GO supported Au clusters. On the other hand, with further growth of the seeds, the gaps between Au NPs would become very close. Therefore, the high quantity of hotspots with an intense EM field assured the SERS intensity of our SERS tags. Besides, Raman reporter enriching and additional chemical enhancement properties would also make a contribution. ${ }^{17}$

Because the signal of Au@GO (without Rubpy) could not be detected in solution, $\mathrm{Au} @ \mathrm{GO}$ (without Rubpy) and Au@ Rubpy/L-GO tags were further drop-coated on a clean silicon wafer, followed by air-drying for the Raman determination. As shown in Figure $2 \mathrm{~h}$, the Raman peaks at 1350 and $1580 \mathrm{~cm}^{-1}$ assigned to the $\mathrm{D}$ and $\mathrm{G}$ bands of $\mathrm{GO}^{30}$ were observed for $\mathrm{Au} @$ GO NP. However, their intensity is much weaker than those of the counterpart, which also slightly showed these two bands but were overwhelmed by the strong characteristic peaks of Rubpy. These results clearly revealed the sensitivity improvement by the addition of Raman reporter than with sole GO.

Stability of Au@Rubpy/GO SERS Tags. Recently, 3-D morphology hybrids by wrapping GO onto the surface of metal oxide, ${ }^{35}$ anatase $\mathrm{TiO}_{2},{ }^{36}$ and dye embedded mesoporous silica ${ }^{37}$ NPs showed GO's interesting NP coating properties. In the current work, the controllable aggregation and surface wrapping was achieved in one step by taking advantage of such a feature. To demonstrate the protection ability of the GO shells, the colloidal and SERS signal stability of Au@Rubpy/L-GO SERS tags was tested in various conditions. Figure $3 \mathrm{a}, \mathrm{b}$ shows that there was no obvious variation in the absorption and SERS spectra of Au@Rubpy/L-GO SERS tags in either pH 7.4 phosphate buffered saline (PBS), $0.5 \mathrm{M} \mathrm{NaCl}$, or $50 \%$ fetal bovine serum solution after slight agitation (reversible, soft agglomeration appeared in $\mathrm{PBS}$ and $\mathrm{NaCl}$, whereas, for $13 \mathrm{~nm}$ 

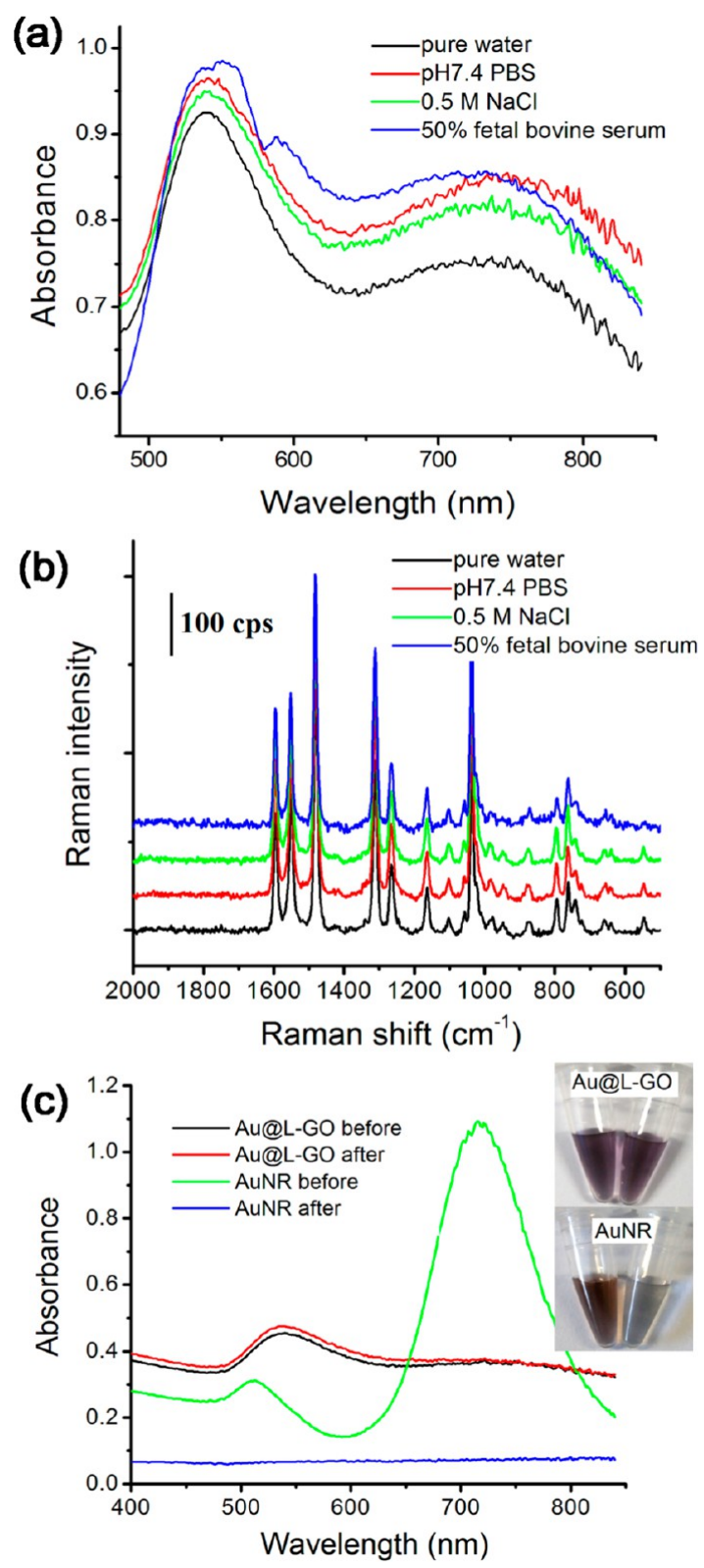

Figure 3. Optical stability of Au@Rubpy/L-GO SERS tags. UV/vis/ NIR spectra (a) and SERS spectra (b) of Au@Rubpy/L-GO SERS tags in water, phosphate buffered saline (PBS), $0.5 \mathrm{M} \mathrm{NaCl}$, and $50 \%$ fetal bovine serum (FBS) solution. Part (c) shows UV/vis/NIR absorption spectra of Au@Rubpy/L-GO SERS tag and AuNR solutions before and after laser irradiation $\left(400 \mathrm{~mW} / \mathrm{cm}^{2}\right.$ for $\left.1 \mathrm{~h}\right)$. The inset photos show Au@Rubpy/L-GO SERS tag and AuNR solutions before (left) and after the laser irradiation (right).

Au NP or AuNR, irreversible aggregates formed in such conditions), illustrating the GO shell's protective effect in serum proteins and at physiological ionic conditions. When stored in water at room temperature, the tags were welldispersed and the SERS intensity was stable in 1 week (Figure S6, Supporting Information). Considering the following photothermal application, the colloidal stability of the tags that encountered $785 \mathrm{~nm}$ laser irradiation was also studied by comparing with the conventional photothermal agent of $\mathrm{Au}$ nanorods (AuNRs) with the longitude absorption of $780 \mathrm{~nm}$. After $785 \mathrm{~nm}$ laser irradiation for $1 \mathrm{~h}$ at $400 \mathrm{~mW} / \mathrm{cm}^{2}$, the AuNR solution totally lost its absorbance, whereas the Au@
Rubpy/L-GO SERS tag sample almost maintained its initial absorbance at the NIR region (Figure 3c). The inset photos show that the color of the AuNR solution changed from dark pink to nearly colorless owing to the heat-induced dramatic irreversible aggregation revealed by the SEM image (Figure S7a, Supporting Information), whereas the color and the morphology of SERS tags showed no apparent change, suggesting the structural stability under laser-induced heat (Figure S7b, Supporting Information).

Thermal-Sensitive Feature of Au@Rubpy/L-GO SERS Tags. Interestingly, although the morphology of SERS tags was unchanged, the SERS intensity in the colloidal sample was found decreased after photothermal treatment. We speculated that the heat generation was responsible for the decrease. Therefore, the relationship between SERS intensity and solution temperature was further carefully studied. As shown in Figure 4a, when the temperature of the tag solution increased from 20 to $40{ }^{\circ} \mathrm{C}$, the SERS intensity slightly decreased to $93 \%$ of the initial value. Upon further increasing the temperature, the SERS intensity decreased dramatically and dropped to about $44 \%$ of the initial value when the temperature
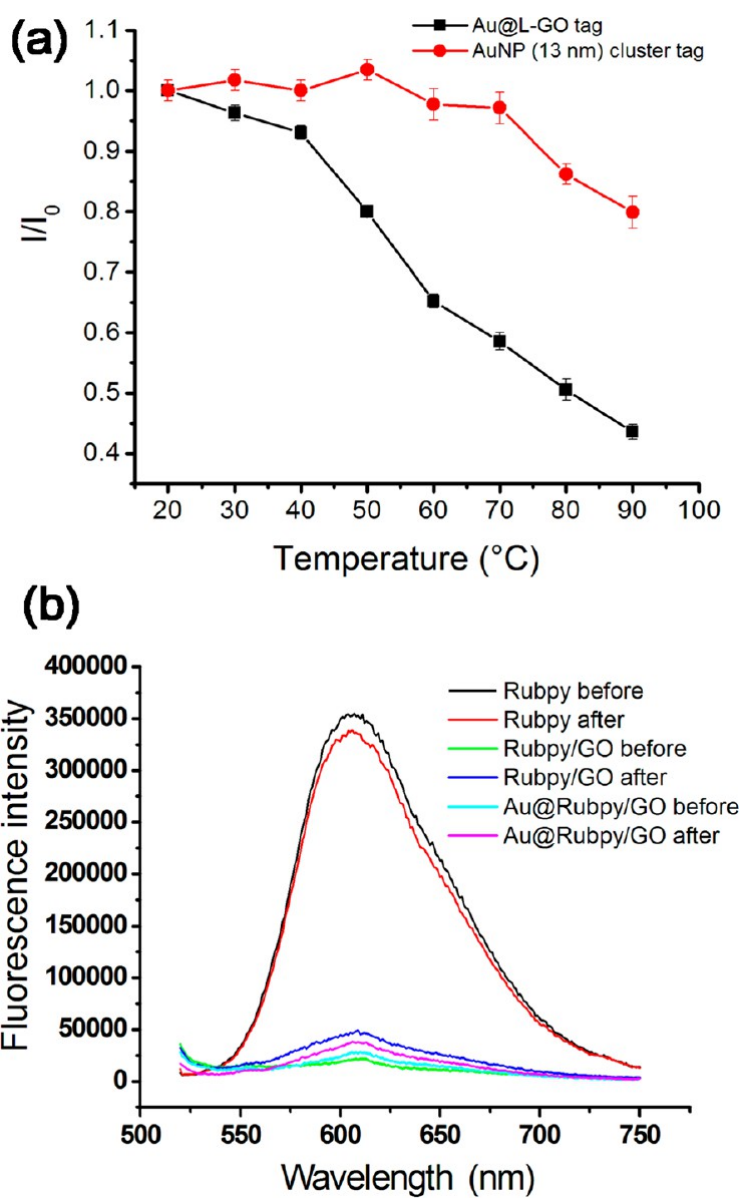

Figure 4. (a) SERS intensity versus temperature profile of Au@ Rubpy/L-GO SERS tag and Rubpy induced aggregation of $13 \mathrm{~nm}$ AuNP cluster protected by thio-BSA. $I_{0}$ denotes peak intensity of 1481 $\mathrm{cm}^{-1}$ at $20^{\circ} \mathrm{C}$. Error bars were based on three parallel measurements for each sample. (b) Fluorescence spectra of Rubpy, Rubpy/L-GO complex, and Au@Rubpy/L-GO SERS tag solutions before and after heating to $70{ }^{\circ} \mathrm{C}$ for $30 \mathrm{~min}$. A slight release of Rubpy was detected from both Rubpy/GO complex and Au@Rubpy/L-GO SERS tags after heat treatment. 
was $90^{\circ} \mathrm{C}$. For comparison, the thio-BSA protected Au NP (13 $\mathrm{nm}$ ) cluster SERS tag was tested with a similar procedure. The SERS intensity remained stable when the temperature was increased to $70{ }^{\circ} \mathrm{C}$, and only dropped about $20 \%$ of the initial value at $90{ }^{\circ} \mathrm{C}$, illustrating a very insensitive response compared with that of $\mathrm{GO}$ wrapped tags.

During the heating treatment, several processes may decrease the intensity of Au@Rubpy/L-GO SERS tags: (1) The destruction of $\mathrm{Au}$ clusters and the number of hotspots diminished. The UV/vis/NIR spectra and SEM images of the sample after photothermal treatment had proved that the structure of SERS tags was intact. Therefore, this cannot be the main reason. (2) The loss of Raman reporters in SERS tags, i.e., the detachment of Rubpy on the GO shell. It was reported that the adsorbed drug molecules could be released from GO under photothermal treatment. ${ }^{43}$ Thus, we measured the fluorescence of Rubpy, Rubpy/L-GO complex, and Au@Rubpy/L-GO SERS tags solutions before and after heating to $70{ }^{\circ} \mathrm{C}$ for $30 \mathrm{~min}$. Figure $4 \mathrm{~b}$ revealed that the fluorescent property of Rubpy was almost stable, whereas a little amount of release of Rubpy was detected from both the Rubpy/GO complex and Au@Rubpy/ L-GO SERS tags after heat treatment. Therefore, it can be deduced that the lost of Raman reporters should be partially responsible for the reduction of SERS intensity, but it is not the whole story. (3) The location redistribution of Raman reporters encapsulated inside GO shell. In the process of in situ formation of SERS tags, the positively charged Rubpy molecules served as linking sites of $\mathrm{Au}$ seeds and GO before $\mathrm{Au}$ NPs' further growth, forming clusters and being wrapped. Therefore, the probability of the appearance of Rubpy at hotspots is high. During the heat treatment, the temperature gradient could force GO attached reporter molecules out of confined hotspot spaces and form a circular vortex ring due to thermal diffusion and natural convection. ${ }^{44}$ The duality of enrichment-depletion that was confined in the GO shell made the redistribution of Rubpy in SERS tags, which may decrease the number of Rubpy at hotspots and thus reduce the SERS intensity. Lately, stimulus (analyte, heat, or light) responsive SERS tags have drawn much attention. For instance, Ray's group reported that the SERS signal of gold nanopopcornbased tags can be totally quenched during photothermal treatment due to the deformation of gold NPs and the departure of Raman reporters induced by the breaking of the $\mathrm{Au}-\mathrm{S}$ bond ${ }^{45}$ or DNA double bond. ${ }^{46}$ Herein, we found the thermal sensitive SERS feature of GO wrapped SERS tags deriving from the heat-induced molecule release and wrapping protection properties of GO, which was useful for in situ monitoring of photothermal therapy response.

Photothermal Property of Au@Rubpy/L-GO SERS Tags. Photothermal therapy has been widely developed by combining pulsed laser and nanomaterials, such as gold NPs (such as nanorods, ${ }^{33,47}$ nanocages, ${ }^{48}$ nanostars, ${ }^{45,49,50}$ and nanoclusters ${ }^{51,52}$ ), carbon nanotubes, ${ }^{53}$ and their hybrids, ${ }^{10}$ that are able to absorb NIR light irradiation and to release the energy as heat. Certain GO derivatives ${ }^{54,55}$ and NP-GO composites $^{56}$ with strong light-absorbing abilities have been explored in the photothermal killing of cancer cells and bacteria. In our work, the Au clusters' growth in the L-GO shell showed dramatic optical absorbance in the NIR region; thus, we explored the heat converting property. The temperature evolution profile (Figure 5) represented the photothermal efficiency of Au@Rubpy/L-GO upon NIR laser (785 nm, 400 $\left.\mathrm{mW} / \mathrm{cm}^{2}\right)$ irradiation as a function of time. Pure water and the

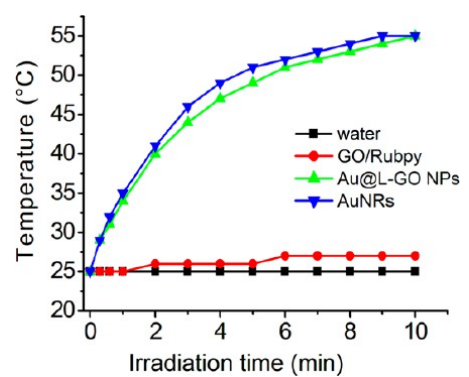

Figure 5. Heating curves of water, the Rubpy/GO, Au@Rubpy/L-GO SERS tag, and AuNR solutions with the same concentration of $\mathrm{Au}$ element under $785 \mathrm{~nm}$ laser irradiation at a power density of $400 \mathrm{~mW} /$ $\mathrm{cm}^{2}$.

precursor of the Rubpy/GO complex solution were utilized as negative controls, and AuNR (the longitude absorption is 780 $\mathrm{nm}$ ) solution with the same concentration of Au element was utilized as a positive control. The temperature of water was stable and that of the Rubpy/GO complex slightly increased from 25 to $27{ }^{\circ} \mathrm{C}$, whereas the Au@Rubpy/L-GO solution showed a drastic change in temperature from 25 to $55^{\circ} \mathrm{C}$ in 10 min, indicating that its heating ability is comparative with that of AuNR (the temperature also increased from 25 to $55^{\circ} \mathrm{C}$, but a little faster).

Bacteria Capturing Capabilities and SERS Detection. To achieve the labeling of bacteria, Au@Rubpy/L-GO was functionalized with glutaraldehyde (GA), which possesses excellent cross-linking properties with peptidoglycan on bacterial cell walls and thus can be used as a capturing agent for both gram-positive and gram-negative bacteria. ${ }^{\text {9,57 }} \mathrm{A}$ cationic polymer, PAH, was used to coat Au@Rubpy/L-GO SERS tags by electrostatic interaction, offering abundant amino groups as reaction sites for further introduction of aldehyde groups. The $\zeta$ potential increased from $-25.8 \mathrm{mV}$ for $\mathrm{Au} @$ Rubpy/L-GO to +48.5 mV for Au@Rubpy/L-GO-PAH. After the reaction with GA, the $\zeta$ potential was measured to be 30.2 $\mathrm{mV}$, a remarkable decrease from that of Au@Rubpy/L-GO$\mathrm{PAH}$ as the result of the consumption of amino groups during the reaction. After the mixing process with GA-modified SERS tags for both bacterial strains, apparent aggregations appeared, illustrating that the tags captured the bacteria and microbial clusters formed. Cluster formation will help to increase the photothermal efficiency due to that they can serve as nucleation centers for laser-induced vapor bubbles. ${ }^{50}$ The TEM images (Figure 6) confirmed the agglutination results. Both S. aureus and E. coli bacteria were efficiently captured by the tags owing to their unique sheetlike coating structural properties combined with the cross-linking ability of GA. Therefore, the heat transfer from the tags to their anchoring bacteria cell walls would be very effective.

Raman signals of $S$. aureus and E. coli bacteria treated with GA-modified Au@Rubpy/L-GO SERS tags were detected by using the excitation wavelength of $632.8 \mathrm{~nm}$. Figure 7 shows dark-field microscope images of the aggregated bacteria labeled with the tags, and SERS spectra at different laser spots across bacteria clusters. Obviously, the bacteria cells (black arrow indicated) were covered by tags with a golden color. Strong SERS signals were recorded from bacteria, while the signals at the blank culture medium were not detected. The high sensitivity of SERS tags rendered the detection of bacteria at the single-cell level easily attainable. Besides, the characteristic Raman signal of Rubpy from the SERS tags remained robust 


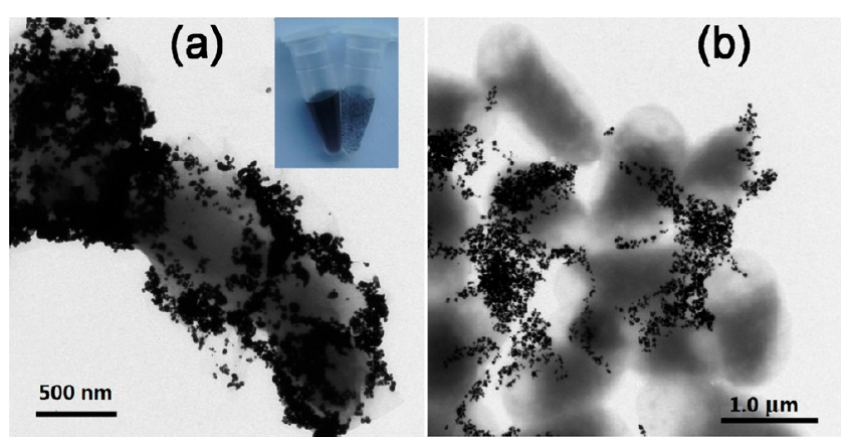

Figure 6. TEM images demonstrating the attachment of GA-modified Au@Rubpy/L-GO SERS tags on S. aureus (a) and E. coli (b) bacteria. The TEM images also show the formation of bigger microbial clusters in the presence of SERS tags. The inset photo shows the GA-modified tag solution before (left) and after (right) addition of $10 \mu \mathrm{L}$ of $E$. coli suspension (OD 0.43). Apparent aggregations could be observed.

and no obvious interference Raman peaks or fluorescence background were obtained.

Antibacterial Photothermal Treatment. To kill S. aureus and $E$. coli, we used $400 \mathrm{~mW}$ of $785 \mathrm{~nm}$ light to expose bacteria attached with GA conjugated SERS tags. The light will be absorbed, and it will generate heat, leading to irreversible bacteria membrane destruction. After irradiation treatment, photothermal lysis of both bacteria was confirmed by colony counting on the tryptic agar plate, and the results are shown in Figure 8a,b. Dish Nos. 1-3 showed the results of $S$. aureus and E. coli alone incubated in PBS buffer (No. 1), incubated in PBS buffer subjecting to NIR irradiation (No. 2), and incubated with $100 \mu \mathrm{L}$ of SERS tags but no NIR irradiation (No. 3), respectively. Dish Nos. 4-6 displayed both bacteria incubated with different volumes $(25,50$, and $100 \mu \mathrm{L})$ of SERS tags after 5 min of NIR exposure prior to culture in Petri dishes. It could be seen that the growth of bacteria after NIR irradiation or solely incubation with tags was affected slightly. In contrast, in the presence of both NIR light and SERS tags, the number of bacterial colonies decreased significantly. Table 1 reveals that the viability is acquired by using the plate counting method. With the increasing the amount of SERS tags added, the bacteria viability continuously decreased, and less than $8 \%$ for E. coli and 3\% for S. aureus bacteria survived after photothermal treatment under the condition in the last column. The results indicated that GA-modified Au@Rubpy/L-GO SERS tags were effective photothermal agents suitable for inhibiting the growth of both gram-positive and gram-negative bacterial strains. To find the relationship between the SERS intensity variation and the antibacterial effect, we simultaneously performed SERS and in situ temperature measurements during the photothermal killing process. Figure $8 \mathrm{c}, \mathrm{d}$ demonstrates that increasing the amount of SERS tags resulted in the increase of the temperature of the photothermal treatment, which led to the decrease of both the SERS intensity of the mixture and the bacteria survival rate. The correlation among SERS intensity decrease ratio, bacteria survival rate, and the terminal temperature of the mixture suspension showed that it is possible to use SERS assay to measure in situ antibacterial response during the photothermal process for both E. coli and S. aureus bacteria.

\section{CONCLUSION}

In summary, we proposed a novel, in situ synthesis strategy for GO wrapped gold SERS tags by using a Rubpy/GO nanohybrid as a complex Raman reporter, inspired by the role of GO as an
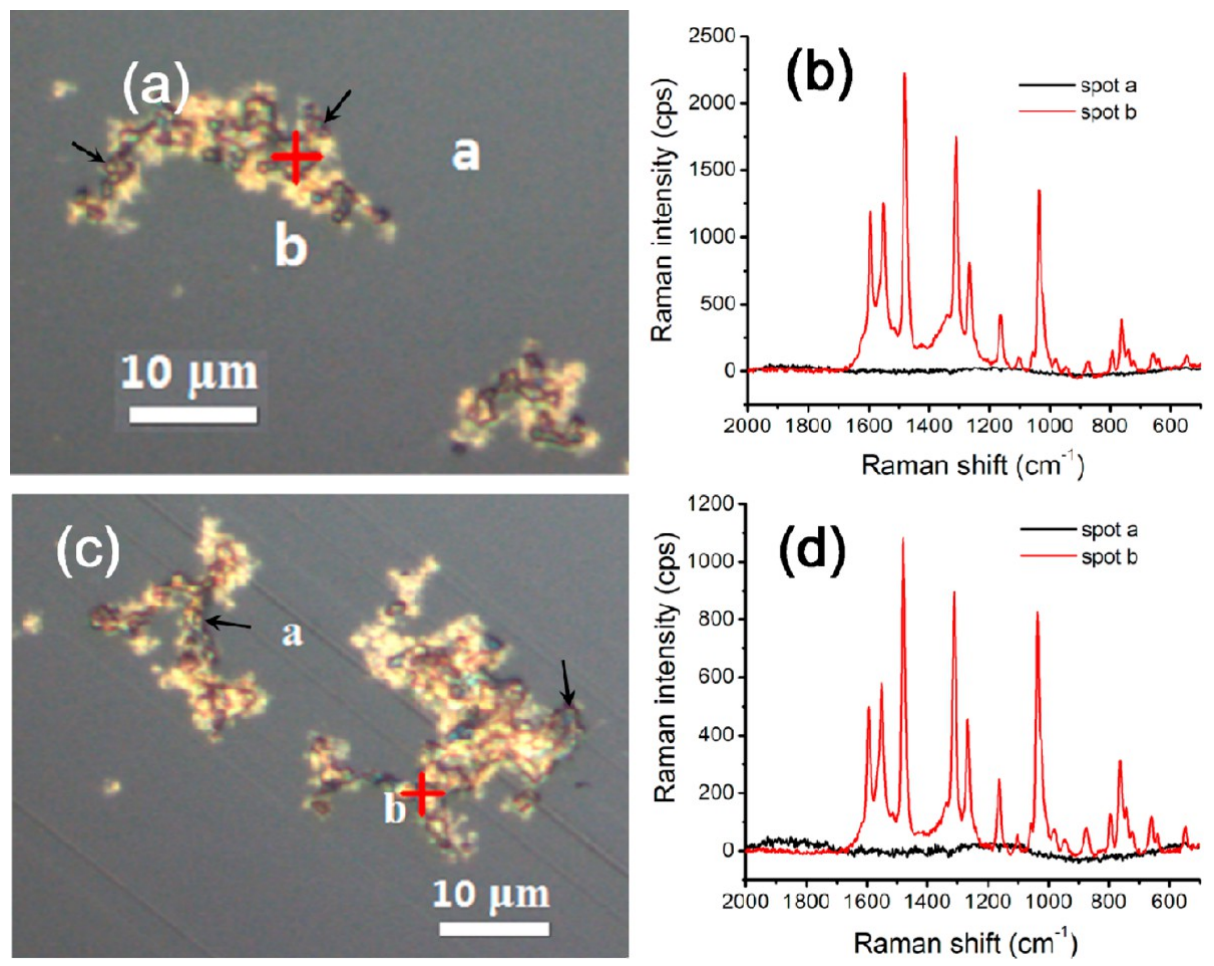

Figure 7. Dark-field microscope images of the aggregated S. aureus (a) and E. coli (c) bacteria labeled with the tags. The bacteria cells are indicated by black arrows. The corresponding SERS spectra at different laser spots across S. aureus and E. coli bacteria clusters are shown in (b) and (d), respectively. 

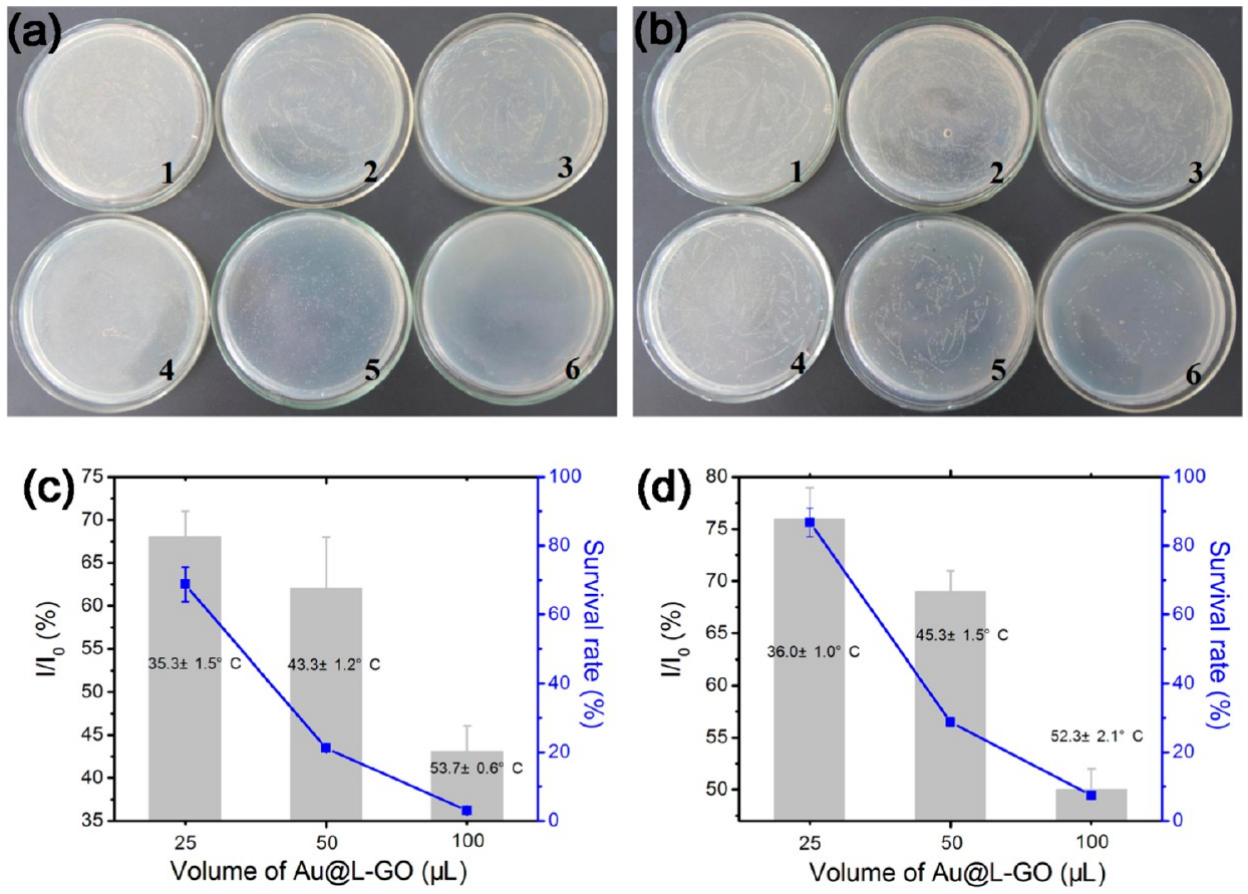

Figure 8. Bacteria growth of $S$. aureus (a) and E. coli (b) after incubation for $12 \mathrm{~h}$. The different bacteria treating conditions including bacteria incubated in PBS buffer (No. 1), incubated in PBS buffer encountering NIR irradiation (No. 2), and incubated with $100 \mu \mathrm{L}$ of SERS tags but no NIR irradiation (No. 3). Dish Nos. 4-6 display bacteria incubated with different volumes (25, 50, and $100 \mu \mathrm{L})$ of SERS tags after 5 min of NIR exposure prior to culture on Petri dishes. Panels (c) and (d) demonstrate the correlation among SERS intensity (peak at $1481 \mathrm{~cm}^{-1}$ ) decrease ratio, bacteria survival rate, and the terminal temperature of the mixture suspension for the cases of $S$. aureus and E. coli, respectively.

Table 1. Survival Rate of the Bacteria after Photothermal Treatment

\begin{tabular}{|c|c|c|c|c|c|c|}
\hline \multirow[b]{2}{*}{ bacteria stain } & \multirow[b]{2}{*}{ bacteria only } & \multicolumn{5}{|c|}{ survival rate $\left(N / N_{0}\right)^{a}(\%)$} \\
\hline & & bacteria + NIR & $\begin{array}{l}\text { bacteria }+ \text { tag } \\
\quad(100 \mu \mathrm{L})\end{array}$ & $\begin{array}{l}\text { bacteria }+ \text { tag } \\
(25 \mu \mathrm{L})+\mathrm{NIR}\end{array}$ & $\begin{array}{l}\text { bacteria }+ \text { tag } \\
(50 \mu \mathrm{L})+\mathrm{NIR}\end{array}$ & $\begin{array}{l}\text { bacteria }+ \text { tag } \\
(100 \mu \mathrm{L})+\mathrm{NIR}\end{array}$ \\
\hline E. coli & $100.0 \pm 2.37$ & $97.71 \pm 3.45$ & $98.76 \pm 3.26$ & $86.77 \pm 4.12$ & $28.70 \pm 1.36$ & $7.45 \pm 0.23$ \\
\hline S. aureus & $100.0 \pm 1.67$ & $97.73 \pm 0.90$ & $95.26 \pm 2.73$ & $68.75 \pm 5.01$ & $21.16 \pm 1.09$ & $2.98 \pm 0.49$ \\
\hline
\end{tabular}

artificial receptor for various dyes. In this synthesis method, the morphology and optical properties of the Au@Rubpy/GO SERS tag can be controlled by using different-sized GO. Because of the synergic effects of GO and the Raman reporter, much stronger and more characteristic Raman signals can be obtained compared with those of conventional structured $\mathrm{Au}$ $\mathrm{NP}$ cluster tags or Au@/GO probes using GO itself as the reporter. A thermal-sensitive SERS feature of Au@Rubpy/GO tags was also observed, which was explained as a result of heatinduced release/redistribution of Rubpy adsorbed on GO wrapping shells. After the tag's property investigation, a multifunctional platform based on GO wrapped SERS tags was fabricated for optical labeling, photothermal treatment of bacteria, and monitoring the killing effect via SERS signal response. Sensitive Raman detection and fast imaging of bacteria could be realized, and high killing efficacy for both gram-positive and gram-negative bacteria was achieved by taking advantage of the tag's strong surface plasmon resonance absorption in the NIR region. Our results also demonstrated the correlation among SERS intensity decrease ratio, bacteria survival rate, and the terminal temperature of the tag-bacteria suspension, showing the possibility to use SERS assay to measure in situ antibacterial response during the photothermal process. This work demonstrated the role of GO in regulating the SERS tag's physical and optical properties for the first time, which may open a new avenue for fabricating multifunctional SERS imaging and photothermal platforms that can be applied to nanomedicine and environmental treatment fields.

\section{ASSOCIATED CONTENT}

\section{S Supporting Information}

Additional characterization details of fluorescence titration spectra; DLS characterization of S-GO, L-GO, Rubpy/S-GO, and Rubpy/L-GO complexes; the size distribution of Au NPs in $\mathrm{Au} @$ Rubpy/L-GO tags; the influence of Rubpy/GO concentration on the cluster size; long-term SERS signal stability; SEM images of AuNR and Au@Rubpy/L-GO SERS tag under photothermal treatment; and SEM and UV/vis/NIR absorption spectrum of thio-BSA protected $\mathrm{Au} N \mathrm{NP}(13 \mathrm{~nm})$ cluster SERS tag. This material is available free of charge via the Internet at http://pubs.acs.org.

\section{AUTHOR INFORMATION}

\section{Corresponding Authors}

*E-mail: yqwang@yic.ac.cn (Y.W.).

*E-mail: lxchen@yic.ac.cn. Tel: +86 535 2109130. Fax: +86 5352109130 (L.C.). 


\section{Author Contributions}

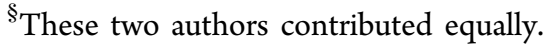

\section{Notes}

The authors declare no competing financial interest.

\section{ACKNOWLEDGMENTS}

We acknowledge financial support from the National Natural Science Foundation of China (81102415, 21275158), the Natural Science Foundation of Shandong Province of China (ZR2010BQ012), the Science and Technology Development Plan of Yantai (2011071), and the One Hundred Person Project of the Chinese Academy of Sciences.

\section{REFERENCES}

(1) Doering, W. E.; Piotti, M. E.; Natan, M. J.; Freeman, R. G. $A d v$. Mater. 2007, 19, 3100-3108.

(2) Li, J.; Chen, L.; Lou, T.; Wang, Y. ACS Appl. Mater. Interfaces 2011, 3, 3936-3941.

(3) Lou, T.; Wang, Y.; Li, J.; Peng, H.; Xiong, H.; Chen, L. Anal. Bioanal. Chem. 2011, 401, 333-338.

(4) Wang, X.; Chen, L.; Fu, X.; Ding, Y. ACS Appl. Mater. Interfaces 2013, 5, 11059-11065.

(5) Chen, L.; Fu, X.; Li, J. Nanoscale 2013, 5, 5905-5911.

(6) Qu, L. L.; Li, D. W.; Qin, L. X.; Mu, J.; Fossey, J. S.; Long, Y. T. Anal. Chem. 2013, 85, 9549-9555.

(7) Wang, Y.; Yan, B.; Chen, L. Chem. Rev. 2013, 113, 1391-1428.

(8) Wang, Y.; Chen, L.; Liu, P. Chem.-Eur. J. 2012, 18, 5935-5943.

(9) Tian, L.; Gandra, N.; Singamaneni, S. ACS Nano 2013, 7, 42524260 .

(10) Wang, X.; Wang, C.; Cheng, L.; Lee, S. T.; Liu, Z. J. Am. Chem. Soc. 2012, 134, 7414-7422.

(11) Georgakilas, V.; Otyepka, M.; Bourlinos, A. B.; Chandra, V.; Kim, N.; Kemp, K. C.; Hobza, P.; Zboril, R.; Kim, K. S. Chem. Rev. 2012, 112, 6156-6214.

(12) Mao, H. Y.; Laurent, S.; Chen, W.; Akhavan, O.; Imani, M.; Ashkarran, A. A.; Mahmoudi, M. Chem. Rev. 2013, 113, 3407-3424.

(13) Chen, D.; Feng, H.; Li, J. Chem. Rev. 2012, 112, 6027-6053.

(14) Wang, Y.; Li, Z.; Wang, J.; Li, J.; Lin, Y. Trends Biotechnol. 2011, 29, 205-212.

(15) Fu, X. L.; Chen, L. X.; Li, J. H.; Lin, M.; You, H. Y.; Wang, W. H. Biosens. Bioelectron. 2012, 34, 227-231.

(16) Fu, X. L.; Chen, L. X.; Li, J. H. Analyst 2012, 137, 3653-3658.

(17) Xu, W. G.; Ling, X.; Xiao, J. Q.; Dresselhaus, M. S.; Kong, J.; Xu, H. X.; Liu, Z. F.; Zhang, J. Proc. Natl. Acad. Sci. U.S.A. 2012, 109, 9281-9286.

(18) Xu, W.; Xiao, J.; Chen, Y.; Ling, X.; Zhang, J. Adv. Mater. 2013, $25,928-933$.

(19) Lu, G.; Li, H.; Liusman, C.; Yin, Z.; Wu, S.; Zhang, H. Chem. Sci. 2011, 2, 1817-1821.

(20) Hu, Y.; Lu, L.; Liu, J.; Chen, W. J. Mater. Chem. 2012, 22, 11994-12000.

(21) Hu, C.; Rong, J.; Cui, J.; Yang, Y.; Yang, L.; Wang, Y.; Liu, Y. Carbon 2013, 51, 255-264.

(22) Lu, F.; Zhang, S.; Gao, H.; Jia, H.; Zheng, L. ACS Appl. Mater. Interfaces 2012, 4, 3278-3284.

(23) Zhang, Z.; Xu, F.; Yang, W.; Guo, M.; Wang, X.; Zhang, B.; Tang, J. Chem. Commun. 2011, 47, 6440-6442.

(24) Xie, Y.; Li, Y.; Niu, L.; Wang, H.; Qian, H.; Yao, W. Talanta 2012, 100, 32-37.

(25) Kim, Y. K.; Han, S. W.; Min, D. H. ACS Appl. Mater. Interfaces 2012, 4, 6545-6551.

(26) Saha, A.; Palmal, S.; Jana, N. R. Nanoscale 2012, 4, 6649-6657.

(27) Liu, Q.; Wei, L.; Wang, J.; Peng, F.; Luo, D.; Cui, R.; Niu, Y.; Qin, X.; Liu, Y.; Sun, H.; Yang, J.; Li, Y. Nanoscale 2012, 4, 70847089.

(28) Huang, J.; Zong, C.; Shen, H.; Liu, M.; Chen, B.; Ren, B.; Zhang, Z. Small 2012, 8, 2577-2584.
(29) Liu, Z.; Guo, Z.; Zhong, H.; Qin, X.; Wan, M.; Yang, B. Phys. Chem. Chem. Phys. 2013, 15, 2961-2966.

(30) Ma, X.; Qu, Q.; Zhao, Y.; Luo, Z.; Zhao, Y.; Ng, K.; Zhao, Y. J. Mater. Chem. B 2013, 1, 6495-6500.

(31) Chou, S. S.; De, M.; Luo, J.; Rotello, V. M.; Huang, J.; Dravid, V. P. J. Am. Chem. Soc. 2012, 134, 16725-16733.

(32) Frens, G. Nat. Phys. Sci. 1973, 241, 20-22.

(33) Yang, X.; Liu, X.; Liu, Z.; Pu, F.; Ren, J.; Qu, X. Adv. Mater. 2012, 24, 2890-2895.

(34) Xie, J.; Zhang, Q.; Lee, J. Y.; Wang, D. I. ACS Nano 2008, 2, 2473-2480.

(35) Yang, S.; Feng, X.; Ivanovici, S.; Mullen, K. Angew. Chem., Int. Ed. 2010, 49, 8408-8411.

(36) Lee, J. S.; You, K. H.; Park, C. B. Adv. Mater. 2012, 24, 10841088.

(37) Sreejith, S.; Ma, X.; Zhao, Y. J. Am. Chem. Soc. 2012, 134, 17346-17349.

(38) Brown, L. O.; Doorn, S. K. Langmuir 2008, 24, 2277-2280.

(39) Tan, X. B.; Wang, Z. Y.; Yang, J.; Song, C. Y.; Zhang, R. H.; Cui, Y. P. Nanotechnology 2009, 20, 445102.

(40) Huang, P. J.; Chau, L. K.; Yang, T. S.; Tay, L. L.; Lin, T. T. Adv. Funct. Mater. 2009, 19, 242-248.

(41) Zhang, P.; Guo, Y. Y. J. Am. Chem. Soc. 2009, 131, 3808-3809.

(42) Li, W.; Guo, Y.; Zhang, P. J. Phys. Chem. C 2010, 114, 72637268.

(43) Kim, H.; Lee, D.; Kim, J.; Kim, T. I.; Kim, W. J. ACS Nano 2013, 7, 6735-6746.

(44) Kang, T.; Hong, S.; Choi, Y.; Lee, L. P. Small 2010, 6, 26492652.

(45) Lu, W. T.; Singh, A. K.; Khan, S. A.; Senapati, D.; Yu, H. T.; Ray, P. C. J. Am. Chem. Soc. 2010, 132, 18103-18114.

(46) Khan, S. A.; Singh, A. K.; Fan, Z.; Senapati, D.; Ray, P. C. Chem. Commun. 2012, 48, 11091-11093.

(47) Zhang, Z.; Wang, L.; Wang, J.; Jiang, X.; Li, X.; Hu, Z.; Ji, Y.; Wu, X.; Chen, C. Adv. Mater. 2012, 24, 1418-1423.

(48) Shi, P.; Qu, K.; Wang, J.; Li, M.; Ren, J.; Qu, X. Chem. Commun. 2012, 48, 7640-7642.

(49) Yuan, H.; Fales, A. M.; Vo-Dinh, T. J. Am. Chem. Soc. 2012, 134, 11358-11361.

(50) Khan, S. A.; Singh, A. K.; Senapati, D.; Fan, Z.; Ray, P. C. J. Mater. Chem. 2011, 21, 17705-17709.

(51) Jung, S.; Nam, J.; Hwang, S.; Park, J.; Hur, J.; Im, K.; Park, N.; Kim, S. Anal. Chem. 2013, 85, 7674-7681.

(52) Tam, J. M.; Tam, J. O.; Murthy, A.; Ingram, D. R.; Ma, L. L.; Travis, K.; Johnston, K. P.; Sokolov, K. V. ACS Nano 2010, 4, 21782184.

(53) Moon, H. K.; Lee, S. H.; Choi, H. C. ACS Nano 2009, 3, 37073713.

(54) Tian, B.; Wang, C.; Zhang, S.; Feng, L.; Liu, Z. ACS Nano 2011, 5, 7000-7009.

(55) Wang, Y.; Wang, K.; Zhao, J.; Liu, X.; Bu, J.; Yan, X.; Huang, R. J. Am. Chem. Soc. 2013, 135, 4799-4804.

(56) Wu, M. C.; Deokar, A. R.; Liao, J. H.; Shih, P. Y.; Ling, Y. C. ACS Nano 2013, 7, 1281-1290.

(57) Gorman, S. P.; Scott, E. M.; Russell, A. D. J. Appl. Bacteriol. 1980, 48, 161-190. 